\title{
Supervision of Plug-in Electric Vehicles Connected to the Electric Distribution Grids
}

\author{
Siyamak Sarabi and Laid Kefsi \\ IFP Energies Nouvelles/Electrical Engineering Department, Rueil Malmaison, France \\ Email: \{siyamak.sarabi-jeiranbolaghi, laid.kefsi\}@ifpen.fr \\ Asma Merdassi and Benoit Robyns \\ Laboratory of Electrical Engineering and Power Electronics (L2EP)/Power system department, Lille, France \\ Email: \{asma.merdassi, benoit.robyns\}@ hei.fr
}

\begin{abstract}
In recent years, automobile industries focus on the electrification and hybridization of the vehicle's production. The number of Plug in Electric Vehicles (PEV) and Plug in Hybrid Electric Vehicles (PHEV) are significantly increasing through the next years. These raises impose negative impacts on the electrical power grids. In this study, a supervision system is proposed with the aim of reducing the power losses and voltage profile improvement, thanks to a dynamic programming optimization algorithm. V2G (Vehicle to Grid) technology is introduced as benefits of vehicle electrification for electrical distribution grids.
\end{abstract}

Index Terms-vehicle to grid (V2G), distribution network, PHEV, PEV, dynamic programming (DP), supervision system operator (SSO)

\section{INTRODUCTION}

Fossil fuels source's limitation and global warming caused by greenhouse gas emissions, are two major current issues of human beings. In France, $26 \%$ of $\mathrm{CO}_{2}$ emissions are dedicated to transportation sector, which is the biggest contributor compared to the energy supply by $13 \%$, buildings by $18 \%$ and industries and agricultures with 20 and a $21 \%$ contribution [1]. According to that, for the sake of reducing fossil fuel dependency and $\mathrm{CO}_{2}$ emission of transportation sector, automobile industries decided to converge to electrification and hybridization of the vehicle's production. This strategy introduces new challenges for electricity suppliers, especially the electrical distribution operators. These problematic challenges consist of voltage deviation, power losses in charging periods, transformer and feeder overloads and power qualities reduction (e.g., voltage unbalance and harmonics increment) [2]. Some ideas such as coordinated charging (smart charging) have been introduced and studied with the aim of reducing the negative impacts [3]. It has been shown that coordinated charging of PHEVs and PEVs can lower power losses and voltage deviation by flattening out peak power and improve the load profile [2], [4]. Consequently, different charging scenarios have been studied to reduce the impact of PHEVs on the electrical networks. One of these scenarios is defined as providing power to help balance loads by "valley filling" (charging at night when demand is low), and "peak shaving" (sending power back to the grid when demand is high) [5]. This definition will introduce new technology named V2G (Vehicle to grid). $\mathrm{V} 2 \mathrm{G}$ is a service which facilitates the vehicles to charge/discharge from/to the grid and acts as a short-term energy storage system [6].

The PHEVs can also act on the ancillary services and control markets. Ancillary services are those services necessary to support the transmission of electric power from producer to purchaser, such as frequency regulation, voltage profile control, system stability, overload prevention and system recovery after blackout [7] and [8] The control market is a marketplace where an actor can be ready to provide back-up power (control power) and energy if something unpredicted would happen [7]. The services in which the PHEV could contribute have been introduced as regulation services (keeping voltage and frequency stable) spinning reserves or control market (i.e. meet sudden demands for power) [5].

The aim of this study is to reduce the impacts of PHEVs and PEVs on distribution networks. These impacts, such as minimizing the power losses, are introducing an optimization problem.

To satisfy the objective, a methodology is proposed to estimate the charging percentage of the vehicle, and determine the available charging and discharging time slot during one day, which leads to the coordinated charging. Dynamic Programming (DP) has been studied for minimum charging cost (price) purpose in [9], where the V2G technology did not consider. Also in [2], the dynamic programming is compared with quadratic programming, where the authors proposed the vehicles as state variable of DP algorithm. This formulation leads to fluctuation in state of charge of the battery and causes harmful effects, e.g., reducing the state of health of the battery. In our study, dynamic programming is applied with the presence of a V2G application (discharge to the grid) and a constraint has been considered to avoid SOC fluctuation. 
This paper is organized by following order: at first, a statistical study related to PEV production in France has been done, to emphasize the importance of the problem and prove the necessity of supervision system, which is presented in Section II. After that the principle of the DP algorithm is proposed in Section III, and DP applied on electric vehicle problem is explained precisely in Section IV. In Section V, a simulation test for supervision system has been done, by using IEEE 13 node distribution test feeder by means of SimPowerSystem toolbox in Matlab/Simulink. The results of the statistical study and simulations are presented in Section VI, and finally the paper is concluded in Section VII.

\section{STATISTICAL STUDIES}

In the national active plan of the Ministry of Ecology, Sustainable Development and Energy (France), particularly in the favor of renewable energy sector in 2010, the global perspective was introduced as production of 450,000 electric vehicles up to 2015 and 2 million electric vehicles by the year 2020 [10]. These predictions seem consistent with the study by IHS Global INSIGHT. The manufacturers forecasting is more optimistic. PSA Peugeot Citroen expects to sell 100,000 electric vehicles by 2015. The other major French manufacturer, Renault, estimated that 2 million electric vehicles will be sold in France in 2020. All these predictions and estimations are showing a growth of electrification demands, which lead to the multiplication of electricity demand as a negative consequence, and the energy storage capability as a positive consequence. For this reason, a narrow frontier, between inconveniences and advantages of this dramatic change, appears and brings new challenges from the electricity supplier's point of view. Here, in Table I, the statistic of existing electric vehicles in the French market with their contribution percentage to the market is presented [11].

The following Estimation has been done to evaluate the capacity for energy storage by the year of 2020, if consider that we will have 2 million electric vehicles with relatively the same market contribution.

TABLE I. Electric Vehicle Production IN France

\begin{tabular}{|c|c|c|c|}
\hline \multirow{2}{*}{ Vehicle Type } & \multicolumn{3}{|c|}{$\begin{array}{c}\text { Sales of electric vehicles in France, } \\
\text { between 2010 and 2013 }\end{array}$} \\
\cline { 2 - 4 } & $\begin{array}{c}\text { Sale market } \\
\text { contribution, } M_{c}(m)\end{array}$ & $\begin{array}{c}\text { Capacity } \\
B a t_{c}(m)\end{array}$ & Battery type \\
\hline Renault ZOE & $23.3 \%$ & $22 \mathrm{kWh}$ & Lithium-ion \\
\hline Bollore Blucar & $17.8 \%$ & $30 \mathrm{kWh}$ & $\begin{array}{c}\text { Lithium } \\
\text { polymer }\end{array}$ \\
\hline Peugeot iOn & $17.3 \%$ & $16 \mathrm{kWh}$ & Lithium-ion \\
\hline Citroën C-Zero & $16.5 \%$ & $16 \mathrm{kWh}$ & Lithium-ion \\
\hline Nissan LEAF & $8.5 \%$ & $24 \mathrm{kWh}$ & Lithium-ion \\
\hline MIA electric & $5.9 \%$ & $8 \mathrm{kWh}$ & $\begin{array}{c}\text { Lithium iron } \\
\text { phosphate }\end{array}$ \\
\hline $\begin{array}{c}\text { Renault Fluence } \\
\text { Z.E. }\end{array}$ & $5.7 \%$ & $22 \mathrm{kWh}$ & Lithium-ion \\
\hline $\begin{array}{c}\text { Smart Electric } \\
\text { Drive (Fortwo) }\end{array}$ & $2.5 \%$ & $16.5 \mathrm{kWh}$ & Lithium-ion \\
\hline others & $2.5 \%$ & $\begin{array}{c}27.44 \\
\mathrm{kWh}\end{array}$ & Lithium-ion \\
\hline
\end{tabular}

This estimation also shows that, how much these new chargeable loads can affect electrical networks by their demand increment. The storage capacity and demand increment $C(n, S O C)$, can be calculated in function of the number of electric vehicles " $n$ " and the vehicles' state of charge "SOC ".

$$
\begin{gathered}
C(n, S O C)=n \times(1-S O C) \times \sum_{i=1}^{m} M_{c}(m) \times B a t_{c}(m) \\
S O C \in[0,1], \quad n \in\left[1,2 \times 10^{6}\right]
\end{gathered}
$$

where $M_{c}(m)$, is the market contribution coefficient of contributor $m$, and $\mathrm{Bat}_{c}(m)$ is the battery capacity of the same contributor. The whole surface response is presented in Fig. 1. At best optimistic point, which will never happen, we can have near to $44 \mathrm{GWh}$ storage capacities, when all 2 million vehicles' batteries are completely empty and ready to charge. In real world, the vehicles never have the same state of charge at their charging demand time. So in this study, a normal case with a normal distribution of the state of charge has been considered, where the result is depicted in Fig. 2 in annual order. For this case, mean value of $\mu=0.48$ and standard deviation of $\sigma=0.08$, are considered to generate the normal distribution of the state of charge.

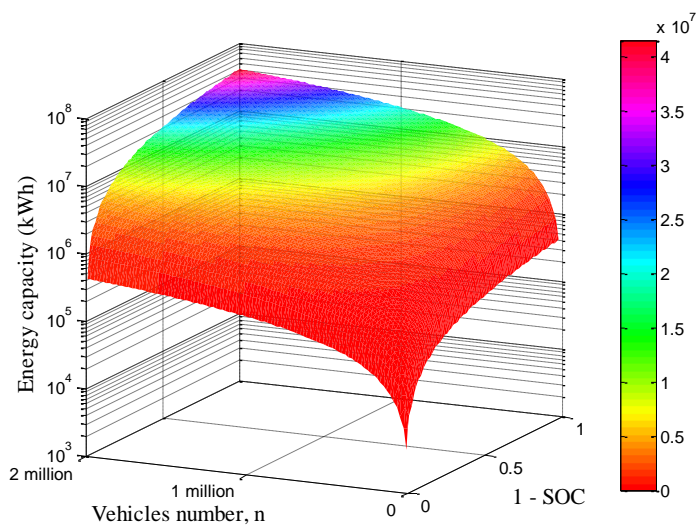

Figure 1. Storage capacity surface.

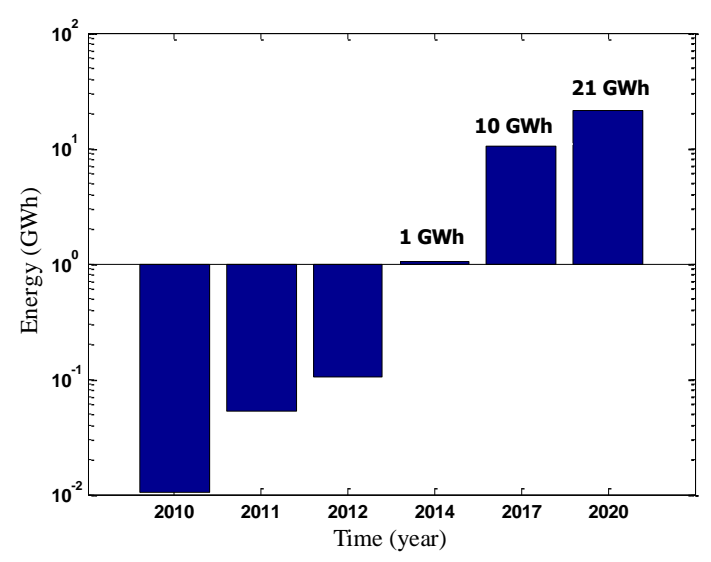

Figure 2. Annual estimation of EV storage capacity.

The Normal distribution function is presented in (2). 


$$
f(S O C, \mu, \sigma)=\frac{1}{\sigma \sqrt{2 \pi}} e^{-\frac{(S O C-\mu)^{2}}{2 \sigma^{2}}}
$$

The obtained result of the normal case shows that, in 2020 the normal storage capacity of $21 \mathrm{GWh}$ will be available. This amount is also huge from electricity suppliers' point of view. If the majority of the available vehicles ask for charging at the same time, a series of harmful effects would occur and cause damage to the whole network. For this reason, different studies have been focused on finding an appropriate solution. For example, coordination charging and alternative demand response with renewable energy sources (e.g., the concept Wind to Vehicle). The $\mathrm{W} 2 \mathrm{~V}$ coordinates the charging time of the vehicles with the wind farm generations [12] and [13]. In this case, the storage capacity of the vehicles can be used to mitigate the intermittency of the renewable energies.

In this paper, we focused on coordination charging with the application of $\mathrm{V} 2 \mathrm{G}$ technology, to decrease the concerns of grid suppliers by proposing a new supervision system, thanks to a dynamic programming algorithm.

\section{DYNAMIC PROGRAMMING}

The principle of dynamic programming (DP) in shortest path problem is to find the optimum path (trajectory) between dedicated start and end point. In dynamic programming, the general problem is broken down into several sub-problems. After that, it starts backward over each point from the final point, by checking the optimum path at each point and considering the optimality of previous sections up to the start point. It is considered to have a problem that can be divided into $n$ different sections ( $n+1$ point). In each section, it is possible to have $j$ possibilities between two points. Then the objective function in this case is presented as follows:

$$
f\left(x_{n}\right)=\min _{j}\left\{c_{j}+f^{*}\left(x_{n+1}\right)\right\}
$$

where $f\left(x_{n}\right)$ denotes optimum path (least cost) from point $x_{n}$ to final point, $c_{j}$ represents the cost of the $j^{\text {th }}$ possibility from point $x_{n}$ to $x_{n+1}$, and $f^{*}\left(x_{n+1}\right)$ is the optimum cost from point $x_{n+1}$ to the final point. For better understanding of the problem, a graphical representation is presented in Fig. 3.

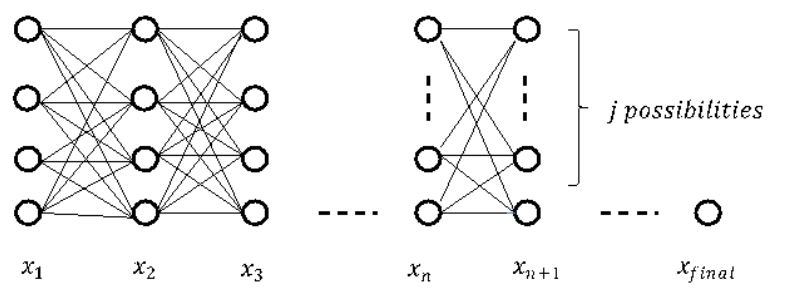

Figure 3. Graphical representation of dynamic programming.

An important point in dynamic programming is that, before solving the problem all the possible paths should be defined.
This point is necessary to guarantee that the optimal path will be finally between the start and the end point of the problem, i.e., inside the search space.

Each possible path has a cost based on the problem priority and definition. The algorithm is going to check the least cost path to reach the next section.

As the algorithm will consider the a priori optimal solution, at the end, the optimal solution proposed by the algorithm could be certainly considered as a global optimum of the problem in the search space.

Always, the algorithm is trying to search for all the possibilities between different sections of the system. So, it is generally time consuming to increase the number of sections in one side, and the number of possibilities on the other side. Therefore, this method, in case of increased number of sections and possibilities, could not be in choice priority. Since, in a problem with $n$ sections and $j$ possibilities, the $j\left({ }^{n-1}\right)$ possibilities could be generated at the final step. So, in this case the whole search space contains $\sum_{i=1}^{n} j^{(n-1)}$ possibilities. Dynamic programming works best on objects, which are linearly ordered and cannot be rearranged (e.g. characters in a string, matrices in a chain, points around the boundary of a polygon, the left-to-right order of leaves in a search tree).

\section{DYNAMIC PROGRAMMING APPLIED ON V2G PROBLEM}

\section{A. Problem Formulation}

One of the points related to electric vehicle problems, which can be similarly solved by dynamic programming, is managing the charging schedule of the vehicles based on the state of charge (SOC) of the battery. To compare this problem with dynamic programming, the initial SOC, which is the SOC of arrival time at home of the vehicles, could be considered as starting point. Also, The final SOC (departure time SOC) could be considered as the final point. Different actions, such as charging, discharging, no charging and charging with variable rate, could be considered as possibilities. Also the sections are defining in time axis, where each sample time of the problem, represents one point (e.g. each $\Delta t$ minutes). Here is an example of one vehicle arriving with a specific amount of energy in its battery. If we consider a PEV with a $20 \mathrm{kWh}$ battery capacity, arriving time at 18:00, the arrival SOC equal to 0.6 and departure time at 7:00, we can define the charging rate as follow:

$$
\begin{gathered}
\alpha=\frac{60}{\Delta t} \\
C_{r}=\frac{P_{\text {outlet }}}{\alpha \times E_{\text {PEV }}}
\end{gathered}
$$

where $\alpha$ is the sample time conversion coefficient from hour to $\Delta t, p_{\text {outlet }}$ is the power of charging station outlet in $\mathrm{kW}, E_{P E V}$ is the battery capacity in $\mathrm{kWh}$ and $C_{r}$ is the charging rate in percentage, which can be considered as 
SOC amount that will be added to the current SOC at each charging sample time. For this case of study, we consider normal charging as:

$$
P_{\text {outlet }}=4 \mathrm{~kW}, E_{P E V}=20 \mathrm{kWh}
$$

So the charging rate will be $C_{r}=0.05$.It means that, after each 15 minutes by choosing charging action, 5 percent charges will be added to the current SOC of the battery. By means of all these definitions, dynamic programming applied to electric vehicle problems are formulated as follow:

$$
\begin{gathered}
f(t)=\min _{j}\left\{c_{j}+f^{*}(t+1)\right\} \\
\operatorname{SOC}(t)=\operatorname{SOC}(t+1)-\left(C_{r} \times j\right)
\end{gathered}
$$

where $j$, in DP model is considered as a possibility, and here is representative of decision factor. It can be chosen "0" for no charging decision and "1" for charging decision. In fact, in this algorithm, discharging decision has been considered as an extra conditional decision to avoid SOC fluctuation, which is defined in the algorithm flowchart. $c_{j}$, represents the cost of possible path $j$ between steps $t$ and $t+1, f^{*}(t+1)$ is introducing the optimum cost from step $t+1$ to the final step, and finally $f(t)$ is the optimum cost from step $t$ to the final step. To obtain a charging schedule of each vehicle, we need to have SOC in function of time which is proposed in (7).

\section{B. Constraints and Possibilities}

For DP applications, always we need to define all the possibilities, going from start point to the end point. In this study, also the possibilities in the form of possible paths have been defined, which have finally created a surface depicted in Fig. 4.

The constraints for the algorithm can be defined as four red dashed lines, depicted in Fig. 4, which are formulated as follow:

$$
\begin{aligned}
& S O C_{\min }(t)=0.3 \\
& S O C_{\text {max }}(t)=1 \\
& \operatorname{SOC}_{\text {backward }}(t)=C_{r} \times t+S O C_{\text {arrival }} \\
& S O C_{\text {forward }}(t)=C_{r} \times\left(t-t_{d}\right)+1
\end{aligned}
$$

where (8) is the minimum SOC line which guarantees available energy in the battery for unforeseen cases, (9) is the maximum SOC line to avoid overcharging, (10) is the backward SOC limit for the recursive approach of the algorithm and (11) is the forward SOC limit for the progressive approach of the algorithm. These two last constraints make sure that the algorithm will never exceed the start and the end points of the search surface. The $t_{d}$, represents the departure time.

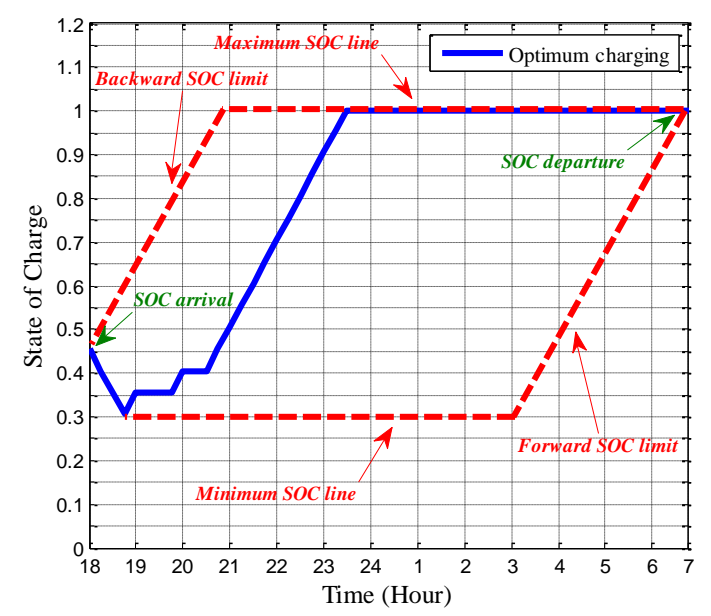

Figure 4. An illustrative example of DP surface compatible with V2G.

\section{Inputs Generation}

For this algorithm, we need to have the cost function for evaluating the different paths based on their costs. In addition, arrival and departure time of each vehicle and arrival state of charge are considered as inputs.

For generating the cost of each possible path, winter Daily Load profile (DLP) of France has been chosen from RTE (réseau de transport d'électricité) website. RTE is the French electricity transmission system operator (TSO). This DLP is considered as charging cost. It means that, charging decision cost at each sample time is based on electricity consumption. By means of this cost strategy, as the DP objective function always is searching for minimum optimum, it is possible to avoid charging at peak hours, and let charging at off-peak hours instead. Consequently, the losses in the network will be minimized. As it is shown in Fig. 5, normalized value of DLP between 0 and 1 is considered as cost of charging, and average value equal to 0.5 is considered as cost of no charging decision. Discharging decision will be made when the vehicle arrives at peak hours, to reduce the peak consumption and participate in peak shaving strategy.

Another strategy, which has been taken in this algorithm, is that the cost signal will be updated for later arrived vehicles. It means that, after defining the vehicle's charging schedule, which arrived at $t=n$, the global cost will be updated with adding to this schedule, and a new global cost will be applied to the next vehicle arriving at $t=n+1$. Thanks to this feature, peak shaving would happen uniformly. Also it imposes the charging demands to the valley of the off-peak hours in DLP. As the huge amount of electric vehicles is not produced yet and information about commute time and arrival SOC are not available, we enforced to use probability functions. Normal distribution has been used in this study to generate three sets of information including, arrival SOC, arrival time and departure time. This information is generated from some general available statistics. To know about mean value and standard deviation for generating normal distribution of arrival and departure 
time, traffic information of the Ile de France region in France, has been considered from real time traffic website, which is presented in lower subplot Fig. 6. The two traffic peaks in working days, particularly represent the commute traffic times. The 18:00 for arrival time at home and the 8:30 for departure time. The standard deviation is considered 2 hours. The generated inputs are plotted in upper subplot of Fig. 6. The arrival SOC is also considered the same as (2), with $\mu=0.48$ and $\sigma=0.08$.

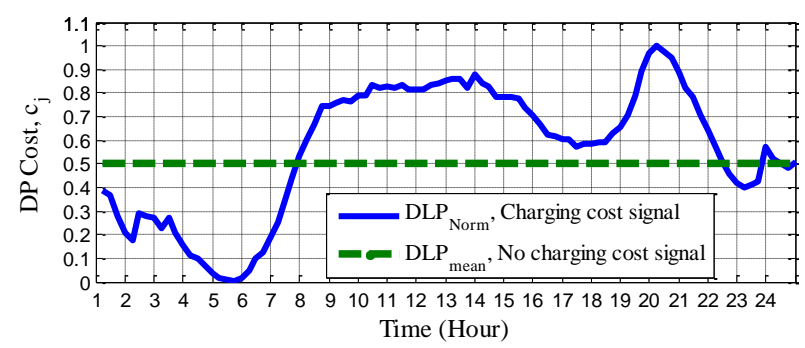

Figure 5. Initial cost signals for DP applications
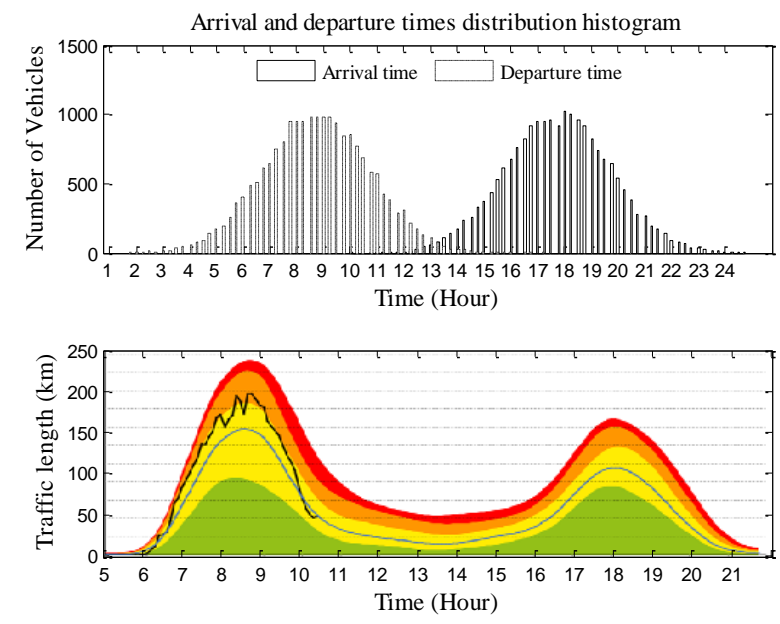

Figure 6. Input generation for arrival and departure time.

\section{Supervision System}

The aim of the supervision system, proposed in this study, is to manage charging time of the vehicles based on information from vehicle owners, to avoid peak charging demands and additionally contribute the vehicles to the power demand response from the grid. Therefore, the only degree of freedom for vehicle owners, is to determine the availability of the vehicles, consists of the arrival and departure time. A communication link between the supervision system operator (SSO) and Battery Management System (BMS), transfers the data related to the battery SOC at the arrival time. Finally, the SSO will send the charging schedule to the vehicle's battery charger. The SSO makes priority list based on the arrival time of the vehicles, and suggests them their charging schedule. The algorithm flowchart applied to the SSO and schematic of supervision system, are depicted in Fig. 7 and Fig. 8 respectively.

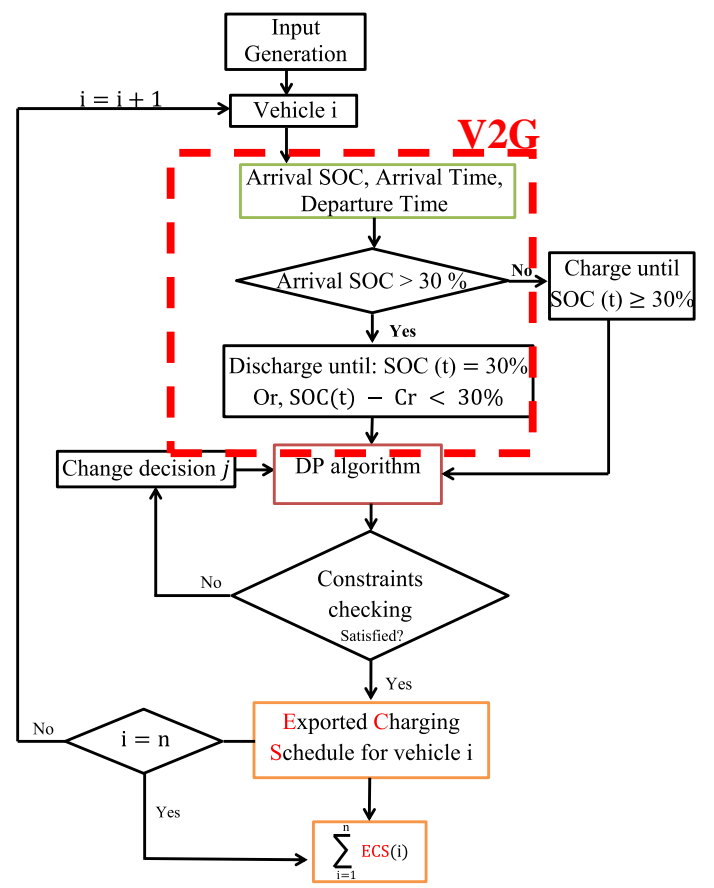

Figure 7. Algorithm flowchart.

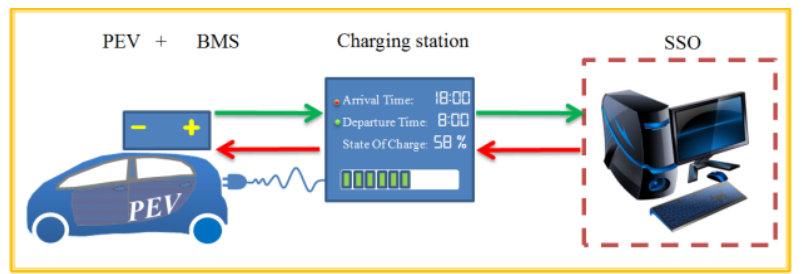

Figure 8. Supervision system schematic.

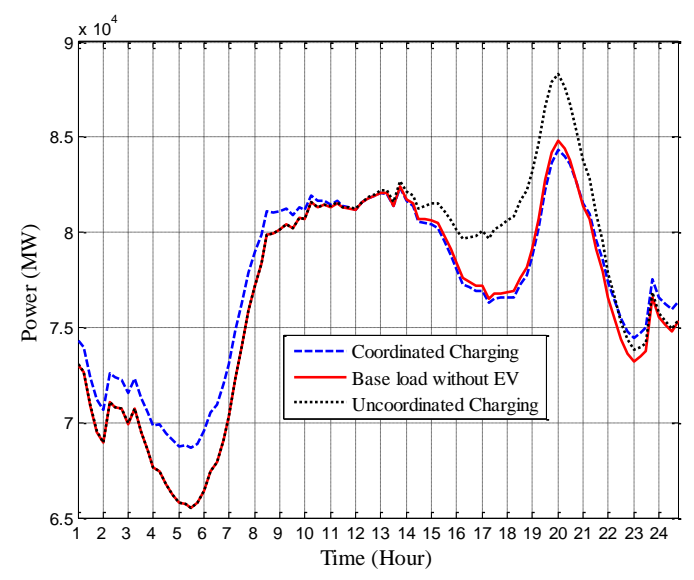

Figure 9. Load profile comparison of base load, uncoordinated and coordinated demand.

By applying the supervision system algorithm for a case of 2 million electric vehicles, the following results are obtained. The impact of coordinated charging is compared to uncoordinated one, Fig. 9. Uncontrolled Power demand with the one that the supervision system offers is also compared and depicted in Fig. 10. 


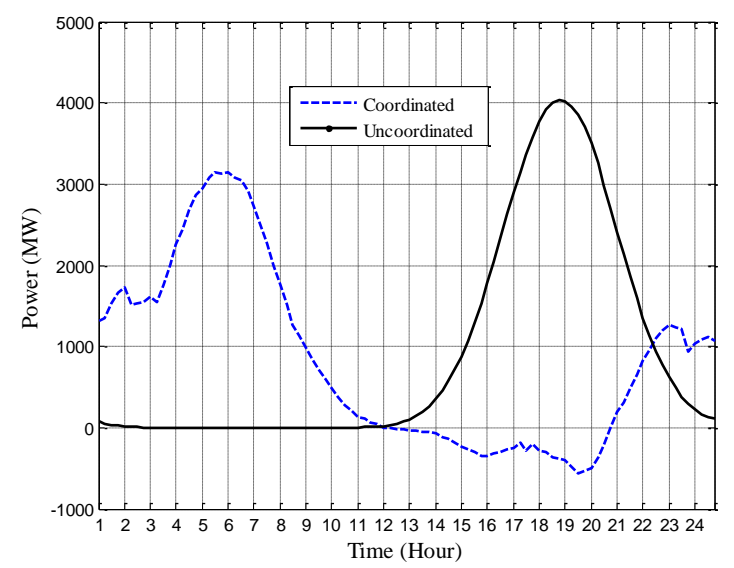

Figure 10. Power demand comparison of PEVs.

These results show that thanks to the supervision system, we succeed to shift power demands of the vehicles' fleet, from peak-hours to off-peak hours. By means of proposed algorithm, peak demand of uncoordinated charging reduced by $18 \%$ compared to coordinated demand. Also, thanks to the V2G technology, $3 \%$ reduction compared to the base load appears. It is important to say that battery limitation, which is imposed to the algorithm, did not let more flexibility to the V2G direction. It could be considered as a compromise between the battery health and the power grid safety.

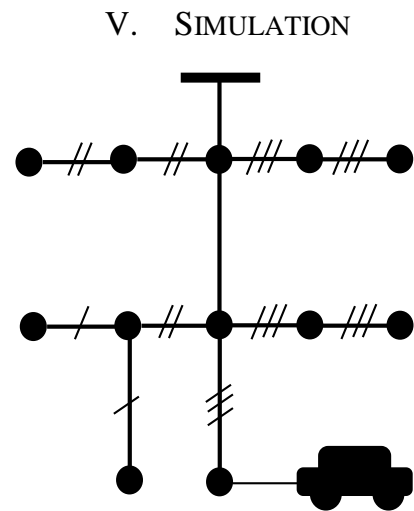

Figure 11. IEEE 13 node test feeder with PEVs charging station.

For testing the proposed supervision system, a simulation study based on IEEE 13 node distribution test feeder has been done. The system layout is depicted in Fig. 11. The model is developed in Simulink, in phasor type, as the continuous time simulation is time consuming. The information related to the resistance, inductance and capacitance of the lines, transformer load conditions and spot and distributed load powers are available in IEEE standards. Different penetration levels of PEVs have been considered. Reference [14] obtained that the capacity of this network for EV charging station is equal to $1.2 \mathrm{MW}$, in case of unity power factor consideration. In this study, we have considered 20, 30, 40 and $50 \%$ penetration level based on the maximum capacity of the charging station, to see the impact of
PEVs charging demand's increment on voltage profile and losses in the lines. In addition, the supervision system is considered in parallel to compare the improvement level of voltage profile and losses reduction. The results of supervised charging are labeled as coordinated, whereas not supervised charging results are marked as uncoordinated.

\section{THE RESUltS}

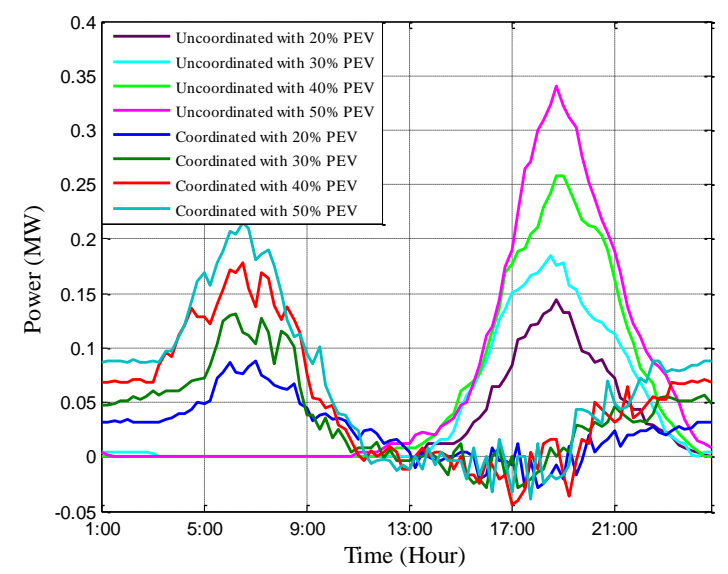

Figure 12. PEVs charging powers.

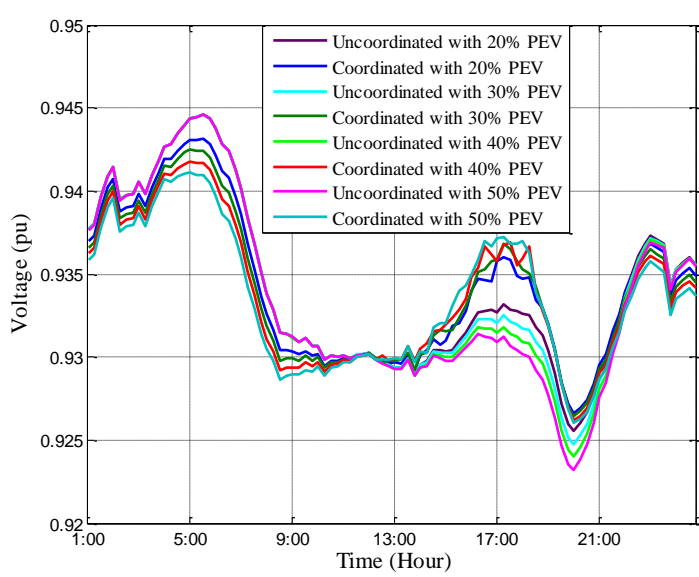

Figure 13. Voltage profile of the network.

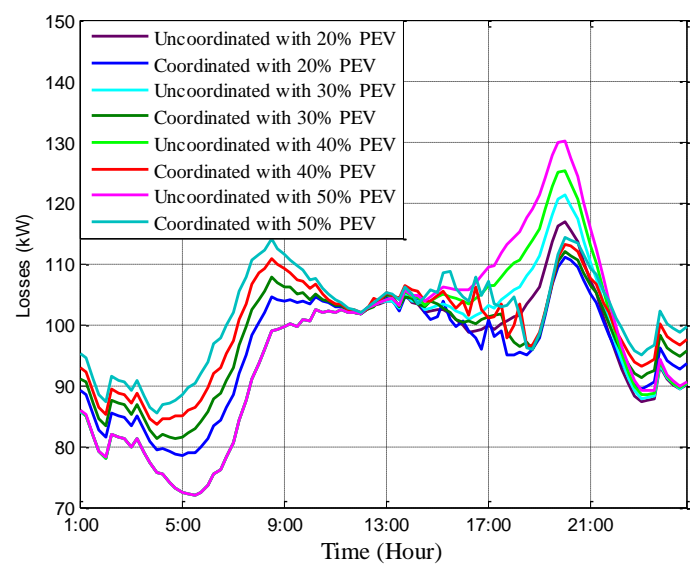

Figure 14. Total losses in the network. 
The results of simulation are presented in Fig. 12 to Fig. 14. In Fig. 12, charging power of arriving vehicles in uncoordinated charging makes a peak demand at 19:00, which is increasing with more penetration level. While in the coordinated charging, the same charging power is distributed after the peak-hours until departure time of the vehicles. So the vehicles will be charged at the off-peak hours from 22:00 to 9:00 approximately. In addition, with the help of V2G application, from 13:00 to 20:00, capable vehicles with respect to their arrival SOC, participate in injecting power to the grid, i.e., vehicle to grid direction.

In the same way, the voltage drop is shown in Fig. 13, where the worst point is related to uncoordinated charging with $50 \%$ penetration at peak-hours. With the help of supervision system, voltage drop at peak demand is reduced. These results could be considered as global optimum, as recursive approach of dynamic programming has been considered, where at each instant the a priori optimal result is taken into account. In addition, an improvement of the voltage profile from 13:00 to 20:00, at the peak-hours, proves the benefits of the applied V2G application. Finally, from network losses point of view, it is shown in Fig. 14 that maximum losses at 20:00 with $50 \%$ penetration is reduced with using coordinated charging strategy. Peak-hours charging avoidance is an important criteria from loss reduction point of view, which in this algorithm is implemented successfully. Despite the total 24 hours losses is kept constant, an important peak loss reduction has been successfully considered.

In fact, with charging the vehicles at the valleys of DLP, the losses during the peaks have been avoided just with shifting the charging time, constrained to the vehicle owners' priorities and the battery health conditions.

\section{CONCLUSION}

In this study, a statistical estimation proved the importance of the increased integration of the electric vehicles and their harmful effects on the distribution grid respectively. Consequently, to cope with the future problems of PEVs charging demand, a Supervision System Operator, with the aim of power losses reduction and voltage profile improvement is presented. The charging schedule for each vehicle is defined by the SSO, with respecting the vehicle's battery constraints and the vehicle owners' priorities. Thanks to this system, a compromise between distribution grid operating point and PEV battery is considered. The algorithm inside the system tries to coordinate the charging time of the vehicles. It has proven that, the $\mathrm{V} 2 \mathrm{G}$ application and the coordinated charging curtail the line losses and voltage drop at maximum loading conditions. The voltage drop and power losses can be reduced by more penetration level of the PEVs to the grid, to prevent overload and damage condition.

\section{REFERENCES}

[1] O. Berruyer. (February 2013). Regional distribution of GHG emissions. [Online]. Available: http://www.les-crises.fr/climat-3pays-emetteurs/
[2] K. Clement-Nyns, E. Haesen, and J. Driesen, "The impact of charging plug-in hybrid electric vehicles on a residential distribution grid," IEEE Trans. on Power Systems, vol. 25, no. 1, pp. 371-380, Feb. 2010.

[3] M. E. Khodayar, L. Wu, and M. Shahidehpour, "Hourly coordination of electric vehicle operation and volatile wind power generation in SCUC," IEEE Trans. on Smart Grid, vol. 3, no. 3, pp. 1271-1279, Sept. 2012.

[4] W. Jian, W. Kuihua, L. Zhizhen, W. Feng, and Z. Yi, "Impact of plug-in hybrid electric vehicles on power distribution networks," presented at the 4th International Conference on Electric Utility Deregulation and Restructuring and Power Technologies (DRPT), Weihai, Shandong, July 66-9, 2011.

[5] U. C. Chukwu and S. M. Mahajan, "V2G electric power capacity estimation and ancillary service market evaluation," presented at the IEEE Power and Energy Society General Meeting, San Diego, CA, July 24-29, 2011.

[6] S. S. Hosseini, A. Badri, and M. Parvania, "The plug-in electric vehicles for power system applications: The vehicle to grid (V2G) concept," presented at the 2nd IEEE ENERGYCON Conference \& Exhibition, Florence, Sept. 2012.

[7] C. Sandels, U. Franke, N. Ingvar, L. Nordstrom, and R. Hamren, "Vehicle to grid-Monte Carlo simulations for optimal aggregator strategies," presented at the IEEE International Conference on Power System Technology, Hangzhou, Oct. 24-28, 2010.

[8] I. Kuzle, D. Bosnjak, and S. Tesnjak, "An overview of ancillary services in an open market environment," presented at the Mediterranean Conference on Control \& Automation MED'07, Athens, June 27-29, 2007.

[9] L. Zhihao, A. Khaligh, and N. Sabbaghi, "Minimum charging-cost tracking based optimization algorithm with dynamic programming technique for plug-in hybrid electric vehicles," presented at the Vehicle Power and Propulsion Conference (VPPC), Chicago, IL, Sept. 6-9, 2011.

[10] C. Touchard. Market statistics of electric vehicles. [Online]. Available: http://www.france-mobilite-electrique.org/marche-etstatistiques-du-vehicule, $880 . \mathrm{html}$

[11] Sale figures and registration of electric cars in France. [Online]. Available: http://www.automobile-propre.com/dossiers/voitureselectriques/chiffres-vente-immatriculations-france/

[12] A. Bouallaga, A. Merdassi, A. Davigny, V. Courtecuisse, and B. Robyns, "Minimization of energy transmission cost and $\mathrm{CO}_{2}$ emissions using coordination of electric vehicle and wind power (W2V)," presented at PowerTech conference, IEEE Power \& Energy Society, Grenoble, June 16-20, 2013

[13] F. K. Tuffner and M. Kintner-Meyer, "Using electric vehicles to mitigate imbalance requirements associated with an increased penetration of wind generation," presented at the IEEE Power and Energy Society General Meeting, San Diego, CA, July 24-29, 2011.

[14] Y. Chen, A. Oudalov, and J. S. Wang, "Integration of electric vehicle charging system into distribution network," presented at the 8th International Conference on Power Electronics and ECCE Asia (ICPE \& ECCE), Jeju, May 30 2011-June 32011.

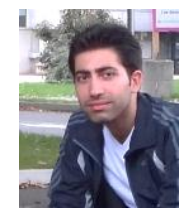

Siyamak Sarabi received his B.Sc. degree in Electrical Engineering from Islamic Azad University of Tehran, Iran in 2010 and M.Sc. degree of Automatic Control from University Joseph Fourier (Grenoble 1), France in 2012, respective- ly. He is now doing his Master in Electr- ical Engineering and Sustainable Develo- pment at University Science and Techno- logy Lille 1, France.

He worked in IKCO as an Electrical Technician from 2008 to 2010, and Noorgostar Ltd. Co. as an Electrical Engineer from 2010 to 2011 in Tehran, Iran. He was with Laboratory GSCOP, Grenoble, France as a Trainee for intelligent buildings energy management project in 2012 . He is now with IFP Energies Nouvelles as a trainee for his master research on V2G applications. His research interests include power systems analysis, mathematical optimization applications on electrical engineering and power electronics on electric vehicle applicat- ions. 


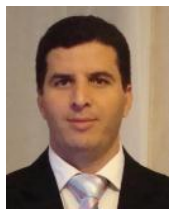

Laid Kefsi was born in Algeria and received his B.E. in Power Electronics and Electrical Drives from Batna University in 1997, Algeria. He received M.Sc. degree from Harbin Institute of Technology, China, in 2001, and the Ph.D. from Valencienne University, Valencienne, France, in 2007. He spent several years at "MGE Schneider Electric" and "Thales Avion- ics", France, as Power Electronics Engineer. Currently, he is working at IFP Energies Nouvelles, France, in power electro- nics and electric vehicles research projects. His research interests include power converters, chargers, battery cell balancing and battery impedance measurement.

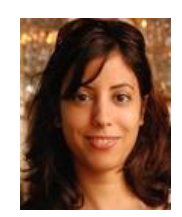

Asma Merdassi was born in Tunisia, and received her B.Sc. from National Institute of Applied Sciences and Technology (INSAT), Tunisia in 2005. She received her Ph.D. in Electrical Engineering from Grenoble Polytechnic Institute, Grenoble, France in 2009. She was with Grenoble Electrical Engineering Laboratory (G2Elab), Gren- oble, France, as a Post-Doctoral Researcher in 2010. In 2011, she joined to the School of High Studies in Engineering in Lille (HEI Lille), France as an Assistant Professor. She is also with the Laboratory of Electrical Engineering and Power Electronics (L2EP), Lille, France, as a Researcher, where she is currently with the Electrical Network and Energetic Systems research team. Her research interests include power system analysis, mathematical optimization, modeling, simulation and control of static converters.

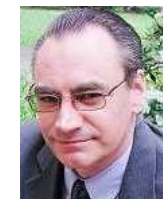

Benoit Robyns (M'96) was born in Brussels, Belgium, in 1963. He received the Electrical Engineering and Doctor in Applied Sciences degrees from the Catholic University of Louvain, Louvain -la-Neuve, Belgium, in 1987 and 1993, respectively, and the Habilitation (HDR) degree from the University Science and Technology Lille 1, Lille, France, in 2000. From 1988 to 1995, he was with the Laboratory of Electrotechnics and Instrumentation at Faculty of Applied Sciences of Catholic University of Louvain, as an Assistant. Since 1995, he has been with the Department of Electrotechnics at the School of High Studies in Engineering in Lille (HEI Lille), Lille, France, where he is currently the Head of the Department. Since 1998, he has been also with the Laboratory of Electrical Engineering and Power Electronics (L2EP), Lille, France, as a Researcher, where he is currently the Head of the Electrical Network and Energetic Systems research team. He is the author and coauthor of more than 100 papers in the fields of digital control of electrical machines, renewable energies, and distributed generation.

Prof. Robyns is a member of the French Society of Electrical and Electronics Engineers, the Royale Belgian Society of Electrical Engineers (SRBE), and the European Power Electronics Association. 